COMECHINGONIA. Revista de Arqueología. Vol. 22, n² 2. Segundo semestre de 2018. ISSN: 0326-7911

\title{
LA CREACIÓN DE UNA DEIDAD: EL CASO DE LA DONCELLA DEL LLULLAILLACO.
}

\section{THE CREATION OF A DEITY: THE CASE OF THE MAIDEN OF LLULLAILLACO.}

\author{
M. Belén Velardez Fresia \\ Instituto de Arqueología y Museo (UNT). San Martín 1545, (4000) Tucumán, Argentina, \\ belenvfresia@outlook.com.ar
}

Presentado: 07/04/2018 - Aceptado: 10/12/2018

\section{Resumen}

El siguiente trabajo constituye una aproximación, mediante un enfoque semiótico, a la significación cultural otorgada a los adornos cefálicos andinos. Múltiples son las evidencias referentes a este particular elemento, pero pocos los estudios respecto de su significación en el pasado. Teniendo en cuenta su materialidad específica y la larga continuidad de tradiciones andinas, que aún incluyen los adornos plumarios en su ritualidad y cotidianidad, logramos una aproximación al rol jugado por estos objetos/agentes dentro de la sociedad inca. El análisis de un contexto incaico particular, la practica ritual conocida como Capacocha, en la cual participó una joven aclla en el volcán Llullaillaco, permite adentrarnos en la comprensión de los procesos de constitución de la identidad personal y el rol de los adornos cefálicos en una interacción constante entre persona/objeto. Son estas relaciones las que van a definir el significado de estos elementos plumarios dentro de las sociedades pasadas.

Palabras clave: arte plumario - ritualidad - Inca - semiótica

\begin{abstract}
The following work constitutes an approximation, through a semiotic approach, to the cultural significance of the Andean cephalic adornments. There are many evidences concerning this particular element, but few studies on its significance in the past. Considering them as corporate emblems, taking into account their specific materiality and the long continuity of Andean traditions, which still include feather adornments in their rituality and daily life, we achieve an approximation to the role played by these objects / agents within Inca society. The analysis of a particular Inca context, the ritual practice known as Capacocha, in which a young woman took part in the volcano Llullaillaco, allows us to enter into the understanding of the processes of constitution of personal identity, and the sacredness of objects in a constant interaction between person/object. It is these relationships that will define the role and meaning of feather adornments within past societies.
\end{abstract}

Key words: feather art - rituality - Inca - Semiotics 


\section{Introducción}

El arte plumario fue desarrollado desde muy temprano por las poblaciones nativas de nuestro continente. Existen evidencias de adornos cefálicos con uso de plumas desde el arcaico tardío, tal como aparece en la Costa Norcentral de Perú y en la Costa Norte de Chile (Gallardo1993; Betancourt 2015). El uso de plumas es una costumbre extendida en toda América: podemos encontrarlas inmersas en distintas prácticas ceremoniales, a través de su participación como ofrendas, vestuarios, etc. Constituye, así, parte del entramado social dentro del cual participa y adquiere un sentido particular. El uso y significado del arte plumario variará de sociedad en sociedad, pero lo que resulta indudable es la importancia otorgada a estos elementos. Los adornos cefálicos andinos con arte plumario fueron poco estudiados en sí mismos, son escasos los especialistas que se dedican a su análisis, quizás esto se deba a que los ejemplares encontrados son relativamente escasos. Muchas de estas piezas cayeron en manos de coleccionistas privados y son poco numerosos los museos que cuentan con una exposición de este tipo de objetos (Betancourt 2015). Sin embargo su fuerte presencia en el seno de las sociedades pasadas está ampliamente documentada, por ejemplo en el arte rupestre o en crónicas coloniales. Diversos autores han mencionado este tipo de elementos y los asocian a objetos de prestigio, sin embargo no fueron el foco de atención y carecemos de información que resulte de un análisis más detallado. El arte plumario supone la articulación de técnicas textiles y de tratamiento de plumas, es por sí mismo todo un campo abierto a ser investigado y aprovechado como fuente de información.

Cabe destacar que en las sociedades andinas el desarrollo del arte plumario no se ha perdido en la actualidad, por el contrario aún puede encontrase formando parte de las celebraciones de estos pueblos. Solo para ilustrar con algunos ejemplos, en la fiesta de quena quena, en los andes Bolivianos, se emplea una cortina con plumas de loro, cuyo color verde recuerda a los sembradíos de papa. En la misma región, la danza de los sikuris se lleva a cabo usando sombreros adornados con plumas de parina (Sigl y Mendoza Salazar 2012) y en el Noroeste argentino los samilantes puneños, utilizan faldellines con plumas de suri para danzar en distintas festividades como la celebración de la Asunción de la Virgen en Casabindo, Jujuy. El siguiente trabajo constituye una aproximación, mediante un enfoque semiótico, a la significación cultural otorgada a los adornos cefálicos plumarios, teniendo en cuenta su participación en un contexto específico.

\section{Signos y Agencia}

El siguiente artículo explora la red de relaciones en las que participaron los adornos cefálicos con arte plumario dentro de la sociedad andina incaica. Este tipo de aproximación se sitúa en la teoría de la agencia y la semiótica Peirciana, donde la materialidad cobra 
importancia y es entendida en base a sus efectos sobre la realidad. Para Peirce el signo es una entidad tríadica: conformada por el representamen, objeto e interpretante (Preucel 2006) ${ }^{1}$. El representamen se define como el signo en sí mismo, es la representación de algo, lo que está en lugar de otra cosa bajo algún aspecto o capacidad (pero no debemos considerarlo como un objeto); se trata de una realidad teórica y mental. El objeto es la denotación formal del signo, es aquel existente al que alude el representamen. Por otra parte, el interpretante no es el intérprete, sino más bien el efecto (o agency) que el representamen produce en el intérprete, y que genera otro signo que nos permite conocer algo más del objeto al que alude el representamen (Marafioti 2005). El signo solo representa a su objeto si hay alguien que correlacione a ambos, y para que ello sea posible debe existir un fundamento sobre el cual realizar la correlación. Con esto vemos, que el signo no es algo que sólo ocurre en la mente de las personas separado del mundo material y sin la influencia de los objetos. Al contrario, la semiótica peirceana está esencialmente basada en el pragmatismo y considera como parte indispensable del proceso de significación al objeto mismo, así como la experiencia sensorial que ellos generan. Es a través de la práctica donde realmente se llega a comprender el significado de los signos o cosas. Charles Peirce ha elaborado una clasificación muy amplia de los signos, sin embargo para los fines de este trabajo nos interesa sólo aquella basada en la relación signo-objeto: ícono, índice y símbolo. En el primer caso la relación entre signo y objeto se establece por semejanza y en el segundo por contigüidad, factorialidad o causalidad. Para entender mejor la indexicalidad pongamos un ejemplo: la veleta de viento, entendida como signo, representa la dirección del viento (este último corresponde al objeto) por acción directa del aire sobre ella (causalidad) y por lo tanto por contigüidad física entre ambos. Para el último caso la relación entre objeto y signo es arbitraria, se trata de un consenso social, como lo es por ejemplo el alfabeto.

Las sociedades, cualquiera sea su lugar y tiempo, se presentan como un todo imbricado, que define y redefine elementos que participan en ellas y, por lo tanto, también a sí mismas. Los significados son establecidos y negociados en contextos habitados por actores sociales humanos y no humanos que ejercen agencia. Esta última se define como la capacidad de producir efectos perceptibles en la realidad (Law y Mol 2008). La agencia, además, puede ser entendida como un fenómeno fundamental en el proceso semiótico, es un aspecto latente en los signos y nos permite comprender como se constituyen sus significados. Pongamos un ejemplo ya utilizado por otros autores (Knappett 2011): los reductores de velocidad son interpretados y entendidos como tales, no solo por un consenso social que los define de esa manera, sino también por la experiencia práctica que cada persona tuvo con ellos. Uno comprende el significado de los reductores de velocidad cuando se ve obligado a reducir la marcha, es decir, afectado por ellos. Asimismo, para poder acercarnos a la significación de los adornos cefálicos, debemos prestar atención a los modos en que estos ejercen agencia dentro de contextos sociales específicos. La agencia está ampliamente distribuida en una red social de relaciones entre entidades, por lo tanto un 
agente va a depender y será producto de las interconexiones con otros elementos (Knappett 2011; Latour 2005). Esto quiere decir que un agente no puede ser entendido por sí mismo, sino a partir de sus relaciones con otros agentes. Esa red constituirá un entramado social que dependerá de un tiempo y un espacio determinado, lo que a la vez la convierte en particular y única. Estos aspectos, también son importantes en la semiótica, donde el contexto es entendido como el conjunto de signos existentes, que aparecen asociados a otro signo según las reglas de integración de la semiosis a la que pertenecen (Magariños de Morentin 2003). El contexto es fundamental, en base a él cada signo adquiere el sentido que le confieren los restantes signos implicados dentro del mismo sistema de relaciones al que alude el contexto. El significado se recupera analizando la presencia de determinados signos en su contexto de utilización.

Nuestro trabajo además propone pensar a los adornos cefálicos como agentes especialmente ligados al cuerpo humano. Según Reynaga Berumen y Vidales Gonzáles (2013: 68) “... es precisamente la naturaleza sígnica del cuerpo la que le permite operar como el capital simbólico mínimo con el cual identificamos nuestra existencia, a la vez que la transmitimos, (...) es un sistema dinámico de significados que interactúan entre sí a la vez que ostentan la sociedad y la cultura en la que el cuerpo se encuentra articulado". Nuestro cuerpo está envuelto en relaciones que configuran su dimensión sígnica, convirtiéndose así, en escenarios de otros signos. Como dijimos al inicio de este párrafo el cuerpo está vinculado a elementos que influyen en su constitución como tal: los perfumes, la vestimenta, los collares, relojes, y demás objetos que lleva uno incorporado en su persona pasan a constituir parte de su identidad y de su definición. El cuerpo, según Gallardo (1993), es un espacio de organización simbólica, un diagrama en el que las sociedades andinas, desde periodos muy tempranos como el arcaico tardío, han privilegiado a la cabeza por sobre el resto del cuerpo. Por esta misma razón los adornos cefálicos son de fundamental importancia en la constitución y expresión del ordenamiento y jerarquización corporal. Los adornos incorporados en las personas permiten observar procesos de producción de sentido, así como la dinámica histórica, mediática y social en la que éstos se construyen (Reynaga Berumen y Vidales Gonzáles 2013). Frente a ello, los adornos cefálicos pueden entenderse como elementos activos dentro de la definición de identidades sociales. A esta visión podemos sumar la idea propuesta por Nielsen (2007) para aquellos objetos de circulación restringida (entre los que propongo considerar a los adornos cefálicos ya que pueden juzgarse elementos escasos debido a los contados ejemplares con los que se cuenta actualmente) que actuarían como emblemas corporativos, a partir de la representación de elementos centrales del modelo cosmológico de las colectividades y posiblemente también de sus jerarquías internas. Mediante su relación sígnica de referencialidad a "otra" cosa, estos objetos podrían ejercer autoridad o poder por sí mismos y/o junto a quien los usa². 
Adentrándonos en el contexto andino, es decir, en la red social en la que se insertan los adornos cefálicos con arte plumario ¿Qué esferas de participación y significación podemos dilucidar en ellos? Para insertarnos en esta problemática se planteó el análisis de los adornos cefálicos con arte plumario, correspondientes a los encontrados junto al cuerpo de una joven Doncella ofrendada en el Volcán Llullaillaco (Salta) en el marco del ritual conocido como Capacocha para el periodo inca. En cuanto a estos elementos se busca comprender no solo su significación si no también la red de relaciones que envuelve a los mismos. La elección de la materia prima, manufactura, uso y semejanzas formales, son algunos de los aspectos que permitirán evaluar la agencia de algunos de los actores (humanos y no humanos) presentes en el contexto. La clasificación de los objetos, considerados como signos, tomando como base la tipología propuesta por Peirce; constituirá una primera aproximación a los sentidos imbricados en los adornos cefálicos.

\section{Un recorrido por el tiempo}

Los adornos cefálicos andinos constituyen parte de una larga y profunda tradición que se remonta a periodos muy tempranos como el arcaico tardío. Para este momento, en la costa pacífica de los andes centrales se registran turbantes consistentes en madejas de finos hilos de lana que se enrollan alrededor de la cabeza y cubren a la misma. Las sociedades que hicieron uso de estos elementos incorporaron en los turbantes plumas para adornar las cabezas. Es importante destacar que estos objetos fueron encontrados en excavaciones arqueológicas sistemáticas, donde pudo registrarse la presencia de turbantes en solo el 40 $\%$ de las tumbas excavadas. No se sabe con certeza si fueron usados en vida o si solo fueron parte del ajuar mortuorio, pero es probable que muestren el acceso limitado a un recurso ajeno a la región: la lana de camélido proveniente de los pueblos altiplánicos, obtenida a cambio de la producción costera. Según Gallardo (1993) la lana fue un bien escaso y por lo tanto de alta valoración social entre los grupos costeros. Los accesorios insertados a estas prendas cefálicas suelen ser elementos únicos o exóticos, evidenciando las conexiones privilegiadas de algunos individuos con proveedores del exterior gracias a su inserción en redes de tráfico con la altiplanicie. Estas prendas también continuaron usándose en momentos posteriores, al parecer con las mismas connotaciones sociales (Agüero 1994; Hermosilla y Barrera 2010). En relación a ello, Agüero (1995) ha llamado la atención sobre el reducido número de individuos hallados portando turbantes en los cementerios arcaicos y formativos. En base a sus análisis de entierros en los sitios Cam-15 AB, AZ-71 y PLM-7, Agüero sostiene que en relación al total de individuos registrados en cada cementerio, entre un décimo y un tercio de la población se enterraban con turbantes. Al mismo tiempo, las escasas huellas de uso en los turbantes sugieren a la autora que sólo se emplearon en situaciones especiales o para el ámbito funerario (Agüero 1995). 
Continuando en el tiempo puede encontrarse un gran desarrollo de los adornos cefálicos a lo largo de los andes, vinculado, a la vez, con una creciente diversidad relacionada a la emergencia de diferentes etnias que utilizan prendas cefálicas particulares como distintivos identitarios, de pertenencia a determinada unidad política o grupo étnico (Berenguer 1993). El "vestido étnico" es un elemento de comunicación no verbal para la interacción humana que dispara procesos afectivos y cognitivos, actúa como marcador superficial que ayuda a posicionar al individuo en el espacio y el tiempo (Museo Nacional de Etnografía y Folklore [Musef] 2014). Así, durante el momento previo a la expansión incaica podemos observar diferentes tipos de gorros.

Uno de ellos, es el gorro de cuatro puntas perteneciente al momento de expansión tiwanakota: un tocado de lana de forma cuadrangular, coronado por cuatro apéndices cónicos en cada esquina. Gorros de este tipo se han hallado en cantidades relativamente grandes en los cementerios de la costa desértica del sur del Perú y, sobre todo, en los valles del extremo norte de Chile. A diferencia de los turbantes arriba mencionados, estos gorros muestran claras evidencias de uso. En la iconografía de estos adornos cefálicos es central la figura de los falcónidos; estas rapaces están dispuestas en pares yuxtapuestos y mirando hacia arriba, formando diseños escalonados. Las puntas del gorro, representan las cabezas de estos falcónidos dirigidas hacia lo alto (en ciertos ejemplares también se representan las alas). Los gorros policromos habrían sido usados por miembros de una elite de funcionarios regionales de Tiwanaku (tal como lo demuestran sus vasos-retratos) en cambio los ejemplares de uno o dos colores habrían sido utilizados por sectores relativamente más bajos en la escala social. La "gente de cuatro puntas" proclamaba a través de esta enseña cefálica su alineamiento político con el Estado altiplánico, así como su forma de adscripción a dicho sistema (Berenguer 1993). Los tocados cefálicos actuaron entre los siglos VII y XII de nuestra era, no solo para definir fronteras sociales y políticas, sino también como distintivo de género; en la cuenca del Titicaca las figuras femeninas no portan ningún tipo de gorro, solo los hombres aparecen vistiendo sus cabezas con estos objetos (Museo Nacional de Etnografía y Folklore [Musef] 2014).

Después de la caída de Tiwanaku, muchos de estos gorros permanecieron en uso entre los habitantes locales aunque con algunas variaciones, en su mayoría eran monocromos o bicromos, con diseños y confección más sencilla, sus apéndices se hicieron más cortos y en ciertos ejemplares desaparecieron por completo, e incluso a otros se les añadieron plumas como ornamentos. En este período hubo un aumento en la diversidad de estos marcadores de identidad, podemos mencionar una amplia variedad de otros tocados, incluyendo gorros de tipo birrete, pasamontañas, cascos gorros semiesféricos, boinas afelpadas (en algunos casos se incluyen apliques de plumas), bandas cefálicas y, para el caso de los pescadores de Arica, diademas de plumas de pelícano (Berenguer 1993, 2006; Horta Tricallotis 2000). Por último cabe mencionar otros tipos de gorros registrados: boinas 
aterciopeladas con penachos $\mathrm{u}$ "orejas", gorros hemisféricos y gorros troncocónicos (Berenguer 1993, 2006). Esta situación puede indicar una redefinición de identidades, que nada tienen que ver con el alineamiento a un Estado sino, más bien, con la reactivación de identidades étnicas antes inhibidas por el mismo.

Durante la conquista incaica numerosas crónicas y documentos coloniales nos hablan de la continuidad del uso de adornos cefálicos como distintivos étnicos, por ejemplo:

“...Dice Pizarro: "los de la una parte de la laguna traen unos bonetones en las caueças, de altor de más de un palmo, tan anchos de arriua como de auaxo; los de la otra parte traen los bonetones de arriua angostos y de auaxo anchos". Aquellos "tan anchos de arriua como de auaxo", parecen aludir a los gorros hemisféricos, que sirvieron de distintivo a los señorios aymaras del norte del lago: los hemisféricos bajos habrían identificado a los grupos collas y los hemisféricos altos, a los canas. En cambio, los "bonetones de arriua angostos y de auaxo anchos", parecen corresponder a los gorros troncocónicos, que operaron como divisa cefálica de los señoríos aymaras que vivian al sur del Titicaca: los troncocónicos monocromos habrían distinguido a los grupos pacajes y los troncocónicos policromos, a los carangas, aullagas y quillacas." (Berenguer 2006: 58).

Incluso señala Cobo (1892 [1653]:230) que el uso inadecuado de los distintivos cefálicos podía ser castigado: "Tenian los de cada nación y provincia, hombres y mujeres sus señales y divisas por donde eran conocidos, y no podían andar sin ellas, ni trocarlas por las de otra nación so graves penas".

El uso de adornos cefálicos no solo se restringía a un diacrítico étnico, también constituía parte de un interjuego mayor dentro de un contexto político y social amplio. "El traje funcionaba a modo de señal exterior de los vínculos territoriales, sociales y políticos del sujeto" (Berenguer 1993:41). Se puede observar claramente como los adornos, para el momento incaico, formaban parte de una gran complejidad y dinámica social; estaban sujetos a restricciones de uso, en cuanto a personas y actividades. Al interior de la sociedad los adornos cefálicos funcionaban como indicadores de posiciones, cualidades y roles diferentes. Olaya Sanfuentes Echeverría (2011) ejemplifica esta situación con una imagen de Guamán Poma donde se aprecia lo siguiente: 


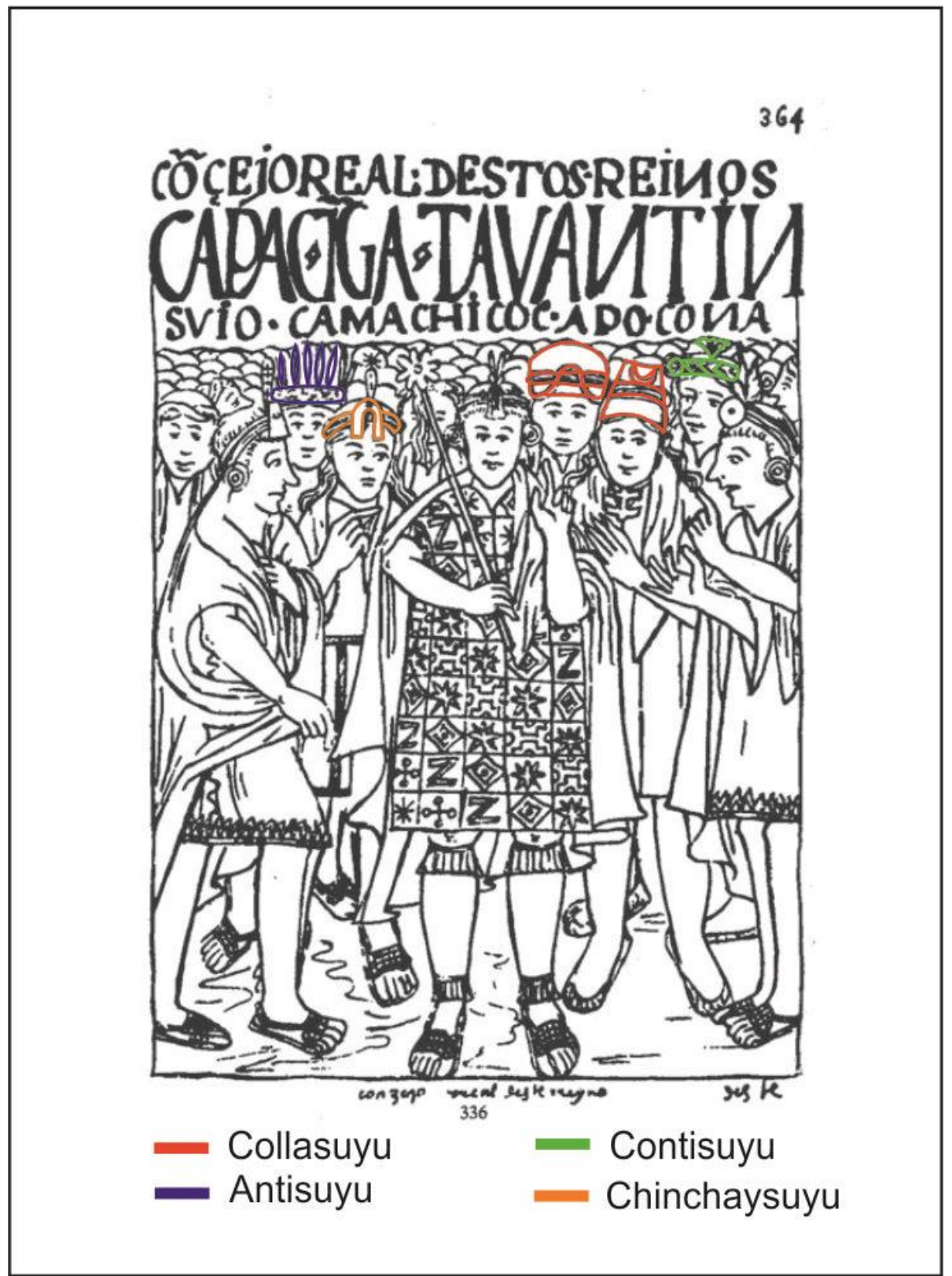

Figura 1: Tomada de Guaman Poma de Ayala (1993 [1615]: 275), corresponde a la página 364 en el original. Esta imagen fue modificada por nosotros.

Los colores en los adornos cefálicos diferencian a los representantes de los suyos incaicos.

El Sapa Inca: exhibe en la cabeza el llautu, un cíngulo que tejían en lana de varios colores, y la masqa paycha, una borla de lana muy fina que iba cosida al llautu y caía sobre la frente. Encima de la borla estaba el tupaqochor, una placa de oro, y sobre ella, en un palo, un pompón emplumado de cuya cima salían tres plumas distintas: 
- El representante del Antisuyu, presenta un tocado con un anillo cefálico emplumado.

- El representante del Condesuyu, posee un anillo cefálico que lleva aplicados una flor en el centro y dos apéndices circulares a los lados.

- El representante del Chinchaysuyu, lleva una especie de cíngulo que presenta en el centro un objeto en forma de " $U$ " invertida, del cual sobresale un largo apéndice que remata en un elemento estrellado.

- Dos exponentes del Collasuyu. El más cercano al Inka luce un gorro de forma semiesférica, ceñido por un cíngulo y con un elemento de forma sinusoidal prendido en el centro. El otro lleva un gorro en forma de cono truncado, igualmente ceñido con un cíngulo, pero con una medialuna como insignia.

Personas pertenecientes al linaje del inca también portan adornos cefálicos tal como los que se observa en esta imagen donde los personajes a sus laterales, en el primer plano, presentan una especie de cíngulo y adornos similares a los de Sapa Inca pero claramente diferenciados.

En el caso de los adornos cefálicos reservados para ocasiones especiales, podemos mencionar el uso de un penacho de plumas llamado pilcocata, el cual era un signo de nobleza utilizado solo en grandes ceremonias (Ceruti 2003). Los adornos cefálicos, como ya se mencionó anteriormente, también actúan en la conformación del género de los individuos hacia el interior de un grupo. Cobo nos ofrece una descripción de las señales que usaban los Collas en la cabeza: "... traían unos bonetes de lana justos pero ahusados, porque asi se amoldaban las cabezas; $y$ sus mujeres unos capillos puntiagudos al talle de capillas de fraile..." (Cobo 1892[1653]: 231)

Los fragmentos citados anteriormente ponen de manifiesto como dentro del Tawantinsuyo, y a su vez al interior de los grupos locales, se emplearon diferentes adornos cefálicos para definir identidades múltiples en las personas. El rango social, ocupación, deberes, servicio ante el imperio, rango etario, género y condición marital, son algunos de los aspectos que pueden expresarse en la vestimenta de las cabezas de los grupos andinos.

Volviendo a las plumas, en cuanto a la manera de conseguirlas podemos hablar de caza, captura e incluso crianza de aves. Guaman Poma cuenta cómo algunos jóvenes (de doce a dieciocho años) mientras cuidaban el ganado, también cazaban aves "cogían con lazos y ligas a los pajaros llamados uachiua, yuto, quiuyo, tacami, abas, recrec, y hacian de la carne petaquillas, y las plumas las guardaban para los Ingas, y Cápac apocona y para Capitanes..." (Guaman Poma 1993 [1615]). Las plumas también fueron un elemento de alto valor tributado al Inca, tal como nos dice Cobo: 
"Las cosas más ricas y de valor como era el oro, plata, piedras preciosas, pluma, ropa fina y deste genero, le solia llevar el mismo cacique de cada provincia o alguno de sus hijos o deudos. En recibiendo el Inca estos tributos, que como esta dicho, era hacienda suya..." (Cobo 1892 [1653]:257)

La Visita de Diez de San Miguel también puede tomarse como ejemplo, en ella se hace mención de la captura de pájaros para el Inca y la tributación con plumajes por parte de ancianos y niños (Betancourt 2015).

En aquellos momentos la posesión de atuendos forrados de plumas, era un privilegio y un símbolo de prestigio reservado para los caciques, al igual que la tenencia de aves exóticas, hasta incluso reparar esas vestimentas. Existieron especialistas maestros tejedores de plumas, denominados Pillcocamayos, quienes gozaban de una posición privilegiada entre la clase artesanal (Betancourt 2015). Las plumas también estuvieron ligadas durante el incanato a una esfera identitaria, el corequenque (Phalcoboenus megalopterus), por ejemplo, se vinculó a la etnia inca, y sus plumas solo podían ser usadas por el Sapa Inca (Gutiérrez Usillos 2002). Como vimos los adornos plumarios formaron parte de múltiples aspectos de la dinámica social incaica, pero siempre gozaron de un elevado valor, ligándose a elementos que marcaban ocasiones especiales o privilegios y posiciones particulares.

\section{Adornos cefálicos vistos desde un contexto sagrado}

En los párrafos anteriores hicimos un recorrido por los diferentes adornos cefálicos utilizados a lo largo de los andes, en los cuales cabe destacar la importancia de las aves en la constitución de más de un tipo de gorro, turbante, etc. En cada uno subyace un sentido particular respecto a la incorporación de aves en el diseño (ya sea a través de la iconografía o del implemento de plumas); pero la recurrencia de su utilización en estos ornamentos muestra una tendencia general. Esto resalta el alto valor otorgado a las aves por estas sociedades, lo que nos lleva a preguntarnos ¿por qué? Quizás una aproximación a la respuesta esté en la existencia de una concepción similar de todos estos pueblos respecto a la interioridad/ fisicalidad de las aves (en el sentido de Descola 2012), derivando así en una cosmología plasmada en objetos que aluden a esa red de interconexión ave/humano. El presente artículo no busca dar respuesta a una problemática tan amplia como ésta, sino más bien a esbozar sus posibles implicancias en la interpretación de los contextos arqueológicos. En este artículo nos interesa destacar la relación ave/humano en el marco del imperio incaico expresada en una ceremonia particular. Vamos a centrarnos en los adornos cefálicos encontrados en el ajuar de una joven aclla en el volcán Llullaillaco (Salta, Argentina). Este contexto fue resultado del ritual conocido como Capacocha, definido como un mecanismo religioso y político de control social que implicaba, la convergencia en la ciudad capital de víctimas sacrificiales y ofrendas procedentes de todo el imperio; 
luego se realizaba la redistribución de las mismas, mediante desfiles y procesiones, hacia su destino final en los confines del Tawantinsuyu, donde los elegidos serian sepultados (Ceruti 2003). Buscamos acercarnos al posible significado de los adornos cefálicos, no sólo desde una perspectiva de distinción étnica sino también como parte integral de otras ideas que expresan la cosmología de un pueblo, así como la vinculación entre humanos y no humanos. La cosmología andina incluye una diversidad de entidades, diferenciadas de los humanos, que poseen injerencia sobre el desarrollo y curso de la vida y la sociedad. Estos seres podrían entenderse como una especie de deidad (Estermann 2006), la cual no refiere a una persona sino a una idea, una abstracción de la inteligencia humana que trata de incluir todo aquello en que participan lo que podría llamarse "dioses":

"...es un "estado" de algo singularizado por una acción numinosa (noumenico) una singular potencialidad, así como la beldad no es la belleza ni la igualdad es lo igual-aún suponiendo la belleza y lo igual- pero beldad e igualdad son manifestaciones de un antecedente, así la Deidad es expresión de Dios" (García Alvarez 2013: 85-86).

Si bien en la cosmología andina no existe un término equivalente para Dios o un vocablo genérico para lo divino, si existen distintas palabras para referirse a diferentes realidades divinas, como por ejemplo los apus y achachilas, las cuales nosotros podríamos equiparar con deidades (Estermann 2006).

\section{La Doncella del Llullaillaco}

Las cumbres más altas de los Andes fueron escenario de hallazgos arqueológicos relacionados al incario; cuerpos congelados de niños y mujeres acompañados de ofrendas suntuarias testimonian rituales acontecidos hace aproximadamente medio milenio. Estos acontecimientos se enmarcan dentro de la ceremonia antes mencionada (Capacocha). Este ritual, es ubicado por Guaman Poma dentro de la fiesta del Inti Raymi y el Capac Raymi, los sacrificios del Cápac ocha se realizaban en el mes de Junio y Diciembre “... para que en el reino haya abundancia de comida para que se sustenten unos y otros, así pobres como ricos..." (Guaman Poma 1993 [1615]: 183). En esta ceremonia se incluían principalmente objetos de oro, plata y mullu, así como comida, vestimenta y bebida. La Capacocha, en ocasiones especiales como la muerte del Inca o catástrofes naturales, incluyó el sacrificio de niños de 10 años o menores, reclutados a lo largo de los dominios estatales, presuntos hijos de señores de las etnias no inca, o bien acllas, jóvenes mujeres elegidas para tal fin (Schobinger 1999). 
Las vidas ofrendadas buscaban propiciar salud y prosperidad mediante la reafirmación de los vínculos con sus apus, a la vez que servían para estrechar lazos entre el centro del estado y los lugares más alejados. La Capacocha fue un mecanismo religiosoeconómico de control social. Dado que todas las provincias participaron en este ritual, evidentemente se fortalecieron las relaciones entre el Cuzco y las provincias, y entre el Inca y los curacas locales. Según D'altroy (2003) la Capacocha condensaba la ideología imperial, en ella se rendía homenaje al Sol reforzando a su vez la legitimidad del linaje del Inka y la red panandina de lugares sagrados. La Capacocha permitió el control simbólico sobre las montañas así como el fortalecimiento de la religión y la política estatal (Vitry 2007).

En 1999, mediante excavaciones en la cumbre del volcán Llullaillaco, se descubrieron tres cuerpos congelados pertenecientes a contextos claramente incaicos. Uno de ellos corresponde a una joven de aproximadamente 15 años de edad, la cual se encontraba adornada con un unku o túnica de lana con motivos de bandas y ajedrezados en azul, rojo y amarillo, plegado sobre el hombro derecho. Llevaba colocado sobre la cabeza, un tocado de plumas blancas. Asociados a ella se encontraron: un aríbalo, una vasija con pedestal, un jarrito con asa cinta, dos platos simples y dos vasijas ornitomorfas, seis chuspas conteniendo alimentos varios, dos keros en miniatura, un peine de espinas, una cuchara y una bolsita de piel de animal conteniendo faneras. De la base del pozo funerario se recuperaron tres estatuillas femeninas: de oro la primera, de plata la segunda y de Spondylus la tercera (Reinhard y Ceruti 2000; Ceruti 2003).

Para evaluar la agencia y significado de los adornos cefálicos con arte plumario, tendremos en cuenta tanto el tocado que la joven llevaba puesto como los penachos que poseen las figurillas de su ajuar.

\section{Análisis de los objetos seleccionados}

A continuación se analizará el adorno cefálico que acompaña a La Doncella y los demás portados por las figurillas pertenecientes al ajuar de la joven. En primer lugar realizaremos la descripción de cada objeto, a partir de lo cual buscamos desglosar los elementos significantes en los adornos cefálicos y sus posibles referentes (en base a relaciones de semejanza, contigüidad, factorialidad, causalidad o consenso). También se evaluará su ubicación en el contexto como un elemento constituyente del sentido de los objetos. Por último discutiremos lo que nuestro análisis ha permitido recabar, complementándolo con información etnográfica y etnohistórica. 
Estatuillas que conforman el ajuar de La Doncella: tres figuras femeninas (todas vestidas, dos con adornos cefálicos)

\section{Ubicación en el contexto}

La tumba Norte del Volcán Llullaillaco (como es llamada en Reinhard y Ceruti [2000]) corresponde a una cavidad de $1 \mathrm{~m}$ de diámetro con una profundidad de 2,30 m, en la cual se encontró a la joven Doncella, cuyo cuerpo se hallaba orientado hacia la dirección Noreste. El fardo funerario adornado con el uncu y el gorro de plumas, presentaba un rico ajuar asociado; a su derecha se halló compuesto por todos los objetos mencionados en el apartado anterior a excepción de las estatuillas, las cuales se disponían del lado contrario hacia la izquierda de la joven.

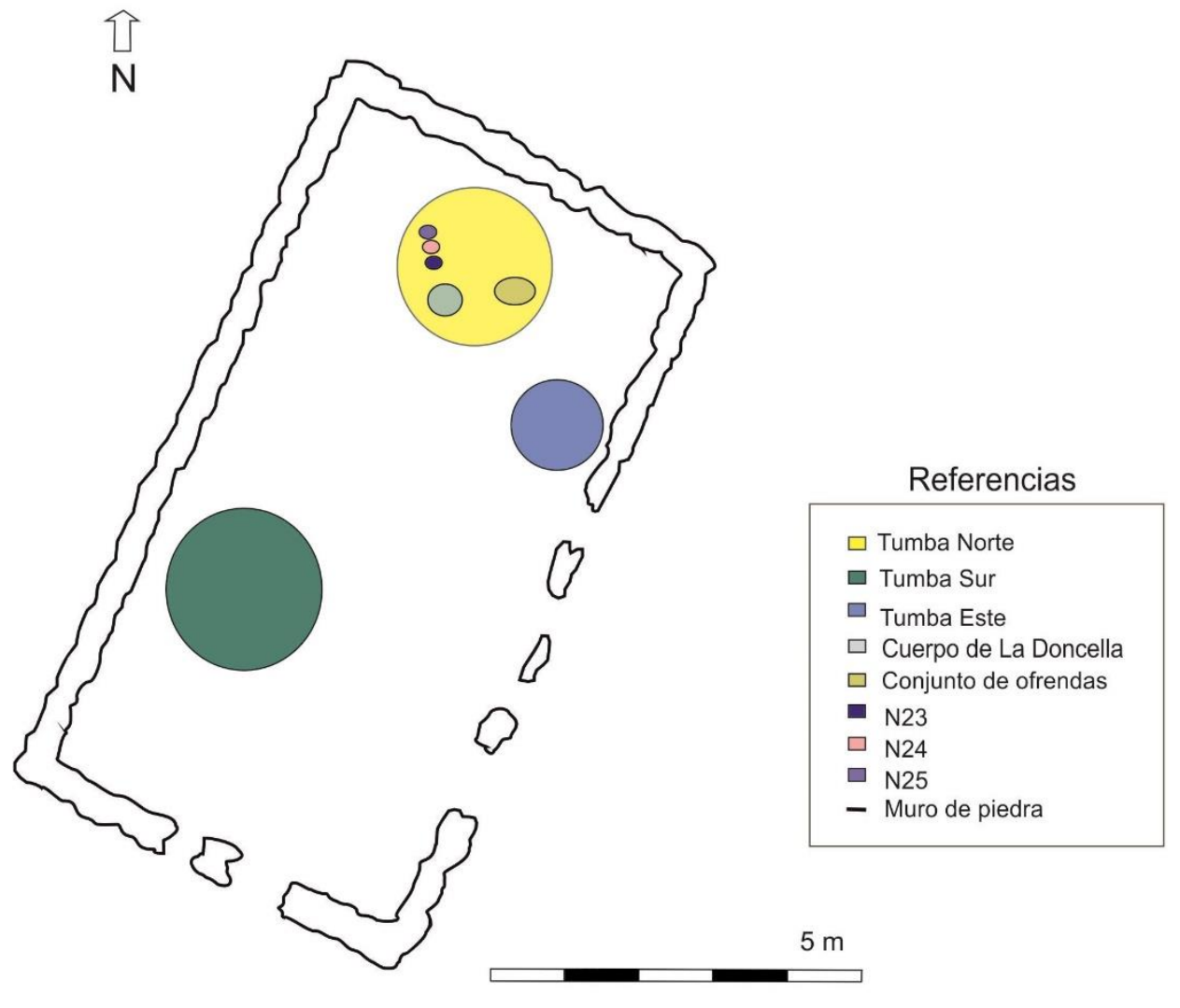

Figura 2: Planta del contexto denominado Tumba Norte. N25: Figurilla de mullu, N24: Figurilla de plata, N23: Figurilla de oro. Tomado y modificado de Reinhard y Ceruti (2000: 146). 
La figurilla elaborada en Spondylus, posee un tamaño de $9,5 \mathrm{~cm}$ de alto y 7,5 $\mathrm{cm}$ de ancho (vestida) y carece de adorno cefálico. Las dos estatuillas restantes sí presentan tocados de plumas. La figurilla elaborada en oro mide vestida $11,5 \mathrm{~cm}$ de alto y $4 \mathrm{~cm}$ de ancho, mientras que la de plata mide vestida 15,5 cm de largo, y 8,5 de ancho (su tocado posee $23 \mathrm{~cm}$ de largo y 12,5 de ancho).

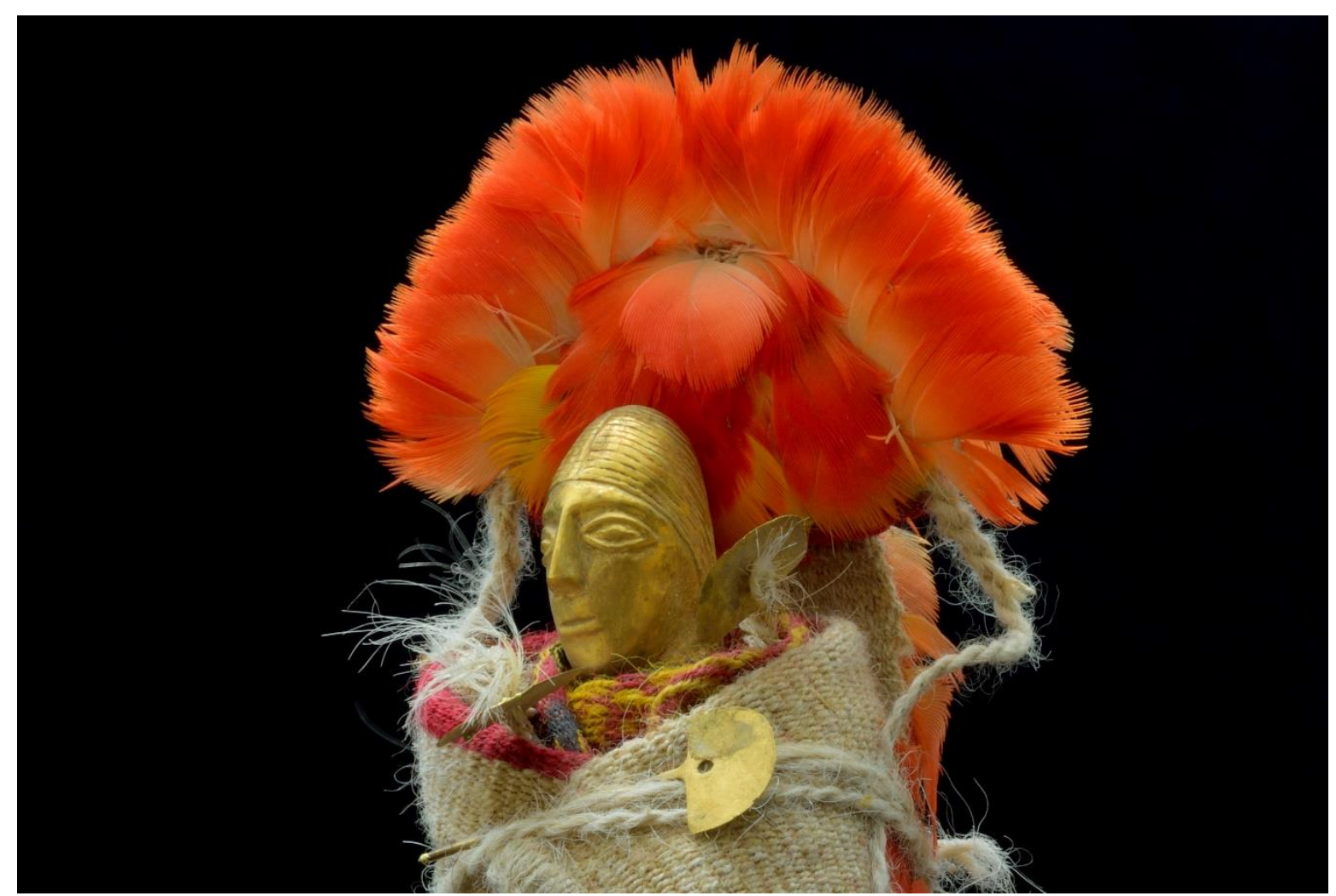

Figura 3: Parte superior del cuerpo de la estatuilla femenina elaborada en oro. Foto: Lisardo Francisco Maggipinto, gentileza MAAM (Museo de Arqueología de Alta Montaña).

Descripción del adorno cefálico de la estatuilla elaborada en oro:

- Color: Rojo anaranjado, blanco y amarillo / sin teñir

- Tamaño: Igual tamaño que el cuerpo de la figurilla en cuanto a longitud.

- Forma: Semicircular

- Plumas: Plumas del cuerpo (semiplumas), de papagayo selvático (Christian Vitry, com. pers. 2015)

- Manufactura: Las plumas fueron cortadas y unidas para dar la forma adecuada al penacho: un semicírculo que rodea a otra semiesfera de plumas amarillas que aparecen por detrás de la cabeza de la figurilla. 


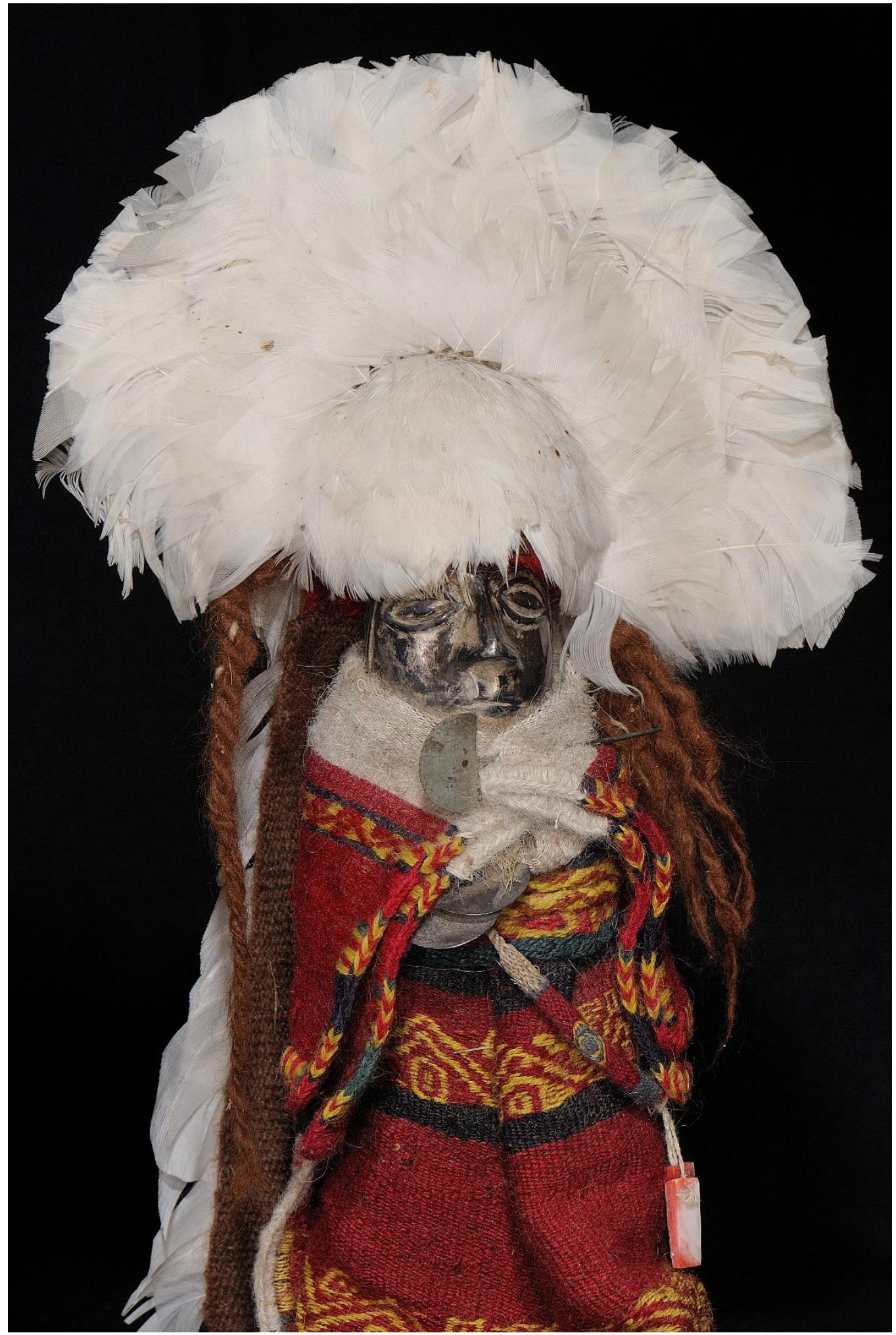

Figura 4: Figura femenina elaborada en plata. Foto: Lisardo Francisco Maggipinto, gentileza MAAM (Museo de Arqueología de Alta Montaña). 
Descripción del adorno cefálico de la estatuilla elaborada en plata:

- Color: Blanco / sin teñir

- Tamaño: Más largo y ancho que el cuerpo de la figurilla.

- Forma: Semicircular.

- Plumas: Plumas del cuerpo (semiplumas), posiblemente correspondan a parina altiplánica.

- Manufactura: Se puede diferenciar un armazón central conformado por un gorro de forma semicircular revestido de plumas y del cual nacen otras, desplegadas hacia arriba y los laterales del mismo.

Las relaciones de tamaño entre los adornos cefálicos y sus respectivas estatuillas no son iguales a la existente entre La Doncella y su tocado. Los penachos de las figurillas presentan dimensiones exageradas respecto al de la joven. En nuestro caso de estudio, los adornos cefálicos no pueden entenderse sin atender a su directa relación con las figurinas, que los convierte por contigüidad física en un índice de ellas. Estos objetos, además son íconos de adornos cefálicos utilizables por personas $y$, por ende, las estatuillas serían ícono de aquellas personas con la posibilidad de usarlos en su cabeza. También por semejanza, ambos objetos, nos recuerdan a las miniaturas que forman parte de ceremonias andinas actuales. Bill Silar (2009) menciona el empleo de las llamadas illas (miniaturas) en contextos rituales domésticos, donde su función está ligada a la productividad y fertilidad. La celebración a la que refiere el autor, se lleva a cabo durante la noche de San Juan en el pueblo de Raqchi (Dpto. de Cuzco), momento en que los hogares se preparan para hacer libaciones y masticar coca sobre un paño ritual, y donde las illas, figuras o piedras que evocan animales, casas, o plantas de cultivo talladas se hacen presentes, actuando como un canal de transferencia desde la gente hacia sus apus. Las illas son, para los pobladores de Raqchi, seres vivientes, que vienen como regalos de las deidades de la montaña (apus). Estas prácticas muestran claras semejanzas con los contextos incaicos donde encontramos elementos compartidos en la escena ritual, por ejemplo el caso de las miniaturas.

Si volvemos a los adornos cefálicos, ahondando en las relaciones icónicas observamos que la forma semicircular de estos objetos puede semejar múltiples cosas; sin embargo centrándonos en los elementos importantes de la cosmología andina, dos de ellas se ofrecen como los referentes más prometedores: el sol y la luna naciente o poniente. En el caso de la estatuilla de oro, hallamos dicha relación fundamentada no sólo en la forma del adorno cefálico sino también en su color anaranjado- amarillo y en la materia prima de la figurilla asociada al sol en el mundo incaico. Por otra parte, el adorno de cefálico en la estatuilla de plata podría referir a la luna, su color es blanco como éste astro, y el mineral que forma el 
cuerpo de la figurilla suele vincularse a esta deidad o a lo femenino (Cobo 1892 [1653]). También podemos pensar en el tocado rodeando al rostro plateado como la irradación de la luna, su inmaculada y fría luz extendida y reflejada en las aguas de lagunas donde habitan las parinas que brindaron las plumas con que se confeccionó el adorno.

No podemos pasar por alto el contraste de colores en los penachos. Cereceda (1990, 2010) ha demostrado mediante su estudio de las talegas y del pájaro llamado alqamari cómo en el mundo andino el color conforma un código, una sistematización cultural que genera una ordenación cromática, de modo que remitan a ciertos significados. El color está dotado de cualidades que constituyen el efecto que produce. En cuanto a ello, en el tocado de la figurina de oro hallamos reproducida la oposición Yahuar Mollo (el color rojizo, la sangre) y Paucar Mollo (el color claro, la pureza, lo resplandeciente) (González Holguín 1989 citado en Mignone 2009), que corresponde a la división del espacio y la sociedad en Hanan y Hurín, Uma y Urco, haciendo alusión a elementos básicos de la cosmología andina y la organización social de estos pueblos. Para el caso de la figurina de plata, el adorno cefálico no presenta colores contrastantes, por lo que este principio no se repite en ella.

Otro aspecto a discutir es la elección de la especie de ave a emplear. Es posible que esta decisión fuera guiada por la necesidad de utilizar un color específico o por el valor del ave elegida. Es sabido que en los andes y sus cercanías las aves forman parte de la cosmología y las mitologías de los pueblos nativos (Levi Strauss 1971; Cereceda 1990; Betancourt 2015; Lewis 2016). También, está documentado el valor otorgado por los incas a los falcónidos, al igual que los cóndores, o algunas aves marinas (Martínez 1989). Por eso, podemos plantear que el uso de plumas puede estar relacionado al valor dado a cada género de ave, así como al poder adjudicado a ellas. Frente a ello nos parece interesante evaluar estas ideas mediante la comparación del adorno cefálico de las figurillas femeninas con el portado por una estatuilla masculina hallada en el mismo volcán pero conformando un conjunto de ofrendas no asociada a ninguno de los entierros. A partir de su comparación, hemos hallado distinciones que podrían darnos indicios respecto a cuál fue el motivo que guió la elección de las plumas. Tomaremos una de las figuras encontradas, para ejemplificar estas diferencias: 


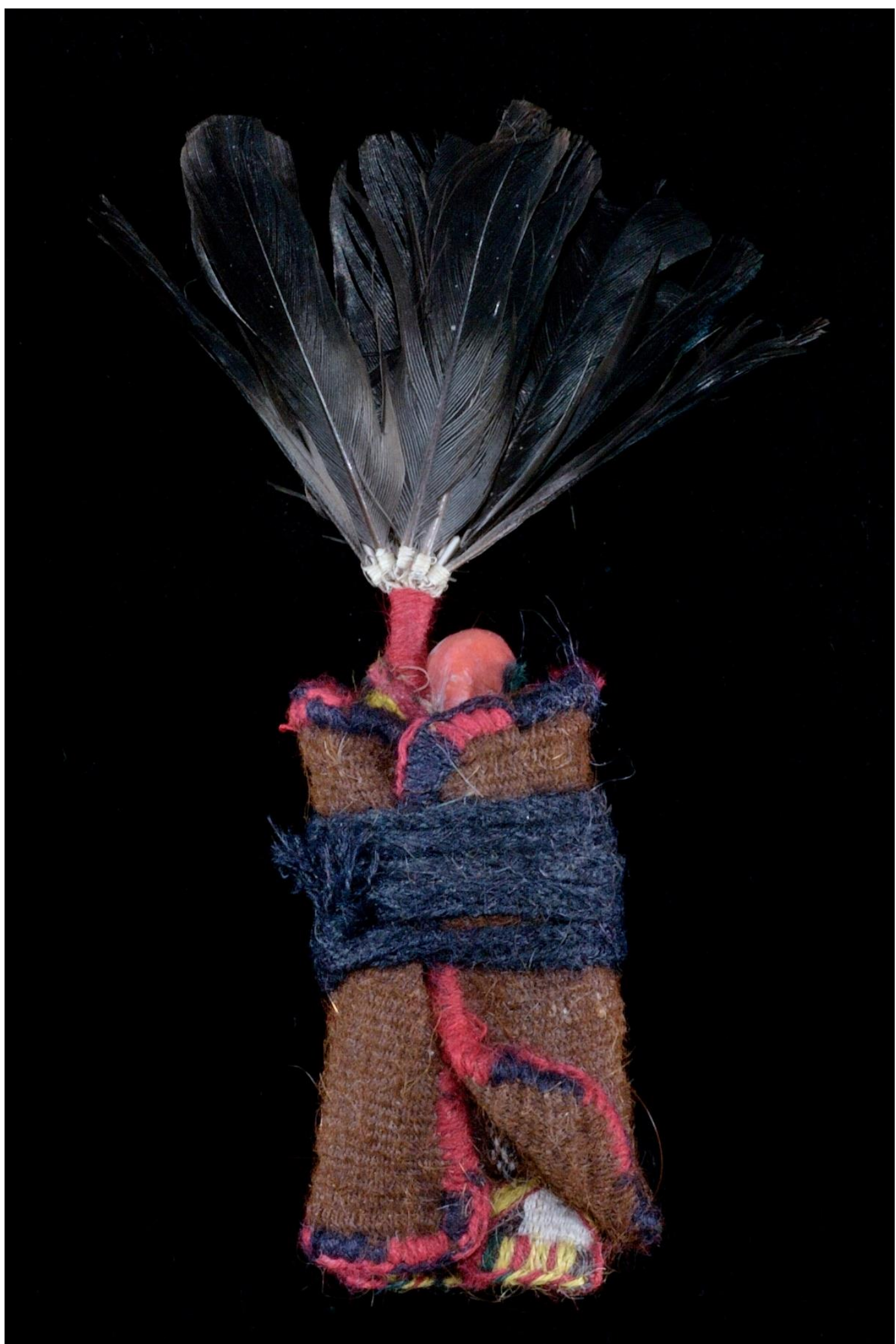

Figura 5. Estatuilla masculina hecha en Spondylus. Foto: Lisardo Francisco Maggipinto, gentileza MAAM (Museo de Arqueología de Alta Montaña). 
Descripción del penacho portado por la figurilla masculina de Spondylus

- Color: Negro-gris / sin teñir.

- Tamaño: Igual al cuerpo de la estatuilla (ésta mide vestida 5,2 cm de alto y 3,5 cm de ancho).

- Forma: Cónica

- Plumas: Plumas de vuelo (timoneras).

- Manufactura : Se trata de un conjunto de plumas unidas por su parte inferior (cálamo) a un palillo de madera mediante un hilo color crudo que las ata a él.

Como vemos la figurilla masculina es diferente en la forma/diseño y el tipo de plumas escogido para su elaboración. Las diferencias halladas podrían estar hablando de distintivos de género o de roles en el incario, respecto a los adornos plumarios. En el caso del adorno cefálico portado por la figurilla masculina, las plumas empleadas son de vuelo, específicamente, corresponden a las timoneras (plumas de la cola encargadas de dar la dirección) lo que podría estar haciendo alusión por causalidad a la acción de volar y dirigir. En el mundo andino, tal como lo muestra Cereceda (1990), existen pájaros al servicio de los dioses tutelares, en sus estudios en la comunidad Chuani (La Paz, Bolivia) los pájaros conocidos como allqamari son considerados como centinelas de las achachilas. En este caso, el ave actúa como mediador entre lo alto y lo bajo. La acción de incluir plumas timoneras en el tocado de la figurilla masculina puede estar relacionada al rol de mediación permitido a partir de la posesión de los instrumentos para el vuelo, que comunica diferentes esferas. Sin embargo, sabemos que sólo con tener plumas no es suficiente para lograr volar, para sostener lo antes planteado es necesario pensar en situaciones de transferencia de cualidades desde un objeto con determinado origen hacia su portador, es decir, la capacidad del vuelo del ave es transferida a la pluma o a quien está en contacto con ella. Otra posibilidad sería que el contacto con la pluma permita la interacción con el ave a la que perteneció y por lo tanto abre un canal de comunicación directa con estos mediadores. Estos acontecimientos han sido explicados por otros investigadores como la creencia en una especie de magia simpática o contagiosa (Frazer 1915), o la acción de un principio analógico (Descola 2012) presente en la cosmología de estas sociedades. A ello podemos sumarle la idea de una contigüidad física primigenia entre pluma-ave que a pesar de haberse quebrado, permanece intacta mediante el proceso semiótico que retorna el referente de la pluma constantemente, así como a sus atributos (los cuales permiten darle sentido). Teniendo en cuenta esto, podemos pensar en los adornos cefálicos como un elemento sobre el que actúa este principio. El ave, a través de sus plumas en los adornos cefálicos, se funde con sus portadores y los influye con sus cualidades, les permite ser agentes de comunicación entre esos espacios diferenciados; lo alto -apus- y lo bajo -el lugar donde viven los humanos-. 
Por otro lado, atendiendo a la forma de este adorno cefálico, cabe mencionar una semejanza entre este y la cabeza de numerosas rapaces, como los caranchos y las águilas, que pueden elevar las plumas de la parte posterior del cráneo. De esta manera podemos decir, que el adorno cefálico es icono de las crestas de estos animales. Las plumas cumplen diferentes funciones, además de emplearse para el vuelo y la protección, también son importantes en la comunicación del ave con otros individuos mediante acciones que las ponen en juego, por ejemplo se extienden en señal de alarma o en momentos de cortejo. Asimismo, las crestas de las aves implican un evento de comunicación específico, siendo signos de algo en particular a lo cual podría asociarse el diseño de nuestra estatuilla. Por esta razón, resulta importante identificar taxonómicamente las plumas del penacho de la figurilla, lo cual puede brindar información útil para su interpretación. En nuestro caso, el penacho es índice de un ave en particular por su relación de contigüidad con ella. Sin embargo no sabemos exactamente de qué especie provienen las plumas ${ }^{3}$ por lo que resulta imposible confirmar la existencia de una relación de semejanza entre la forma del tocado y la disposición de las plumas en las diferentes regiones topográficas del cuerpo del ave o su asociación con una conducta específica.

En el caso de las figuras femeninas la elección de las plumas no podría fundamentarse en la capacidad del vuelo. Ellas corresponden a semiplumas que se ubican en el cuerpo del ave y que sirven para protegerlas. Además este tipo de plumas son similares a las únicas presentes en los pichones de las aves. En este caso, quizá la cualidad que interesaba era la protección y el nacimiento. Asimismo, otro aspecto importante en estos adornos cefálicos es el despliegue del color, claramente logrado en su diseño, ya que este permite su total y máxima apreciación. Como dijimos anteriormente, los colores son importantes porque conforman un código en sí mismo, y ejercen agencia dentro de la sociedad andina. Siracusano (2005), nos recuerda la obra de Bernabé Cobo, donde el color se despliega en todas sus cualidades, no tan solo cromáticas y visuales, sino también políticas, sagradas y hasta curativas: se usaban plumas de guacamayos, granos de maíz o conchas marinas para derramar sobre el enfermo o soplar a las huacas. La dimensión política del color entre los incas queda claramente reflejada en la siguiente cita "el primer privilegio que el Inca dio a sus vasallos fue mandarles que, a imitación suya, trajesen todos en común la trenza en la cabeza. Empero que no fuese de todos colores como la que el Inca traía, sino de un color solo. Y que fuese negro". El color se nos presenta como una forma de estructurar la vida entre las personas, y también entre estas y sus sacralidades. De todas maneras, el diseño de los tocados, no sólo puede estar ligado a la intención de resaltar un color, sino también recuerda al principio que rige en las aves durante los momentos de cortejo y de reproducción, cuando el despliegue de colores es fundamental y suelen extenderse colas y alas en forma de abanicos. Este aspecto refuerza el sentido de fecundidad en las estatuillas. Sin embargo, también debemos tener en cuenta que los colores de las plumas poseen una iridiscencia imposible de imitar con los 
tintes, lo que podría justificar la inclusión de ciertas especies en los adornos cefálicos en pos de otras. En el área andina las plumas no solo cargan en ellas la fuerza de su color, sino también algunos aspectos relacionados con el ave al que pertenecieron, por ejemplo, las plumas rosadas de parina chica están relacionadas a la lluvia y son de buen augurio debido a que la migración de estos animales coincide con la época estival (Sigl y Mendoza Salazar 2012). Esto resulta interesante debido a que uno de los tocados parece estar elaborado con el plumaje de estas aves. En cuanto a la forma, puede hallarse una semejanza con el despliegue de alas en el vuelo o en el momento de copula y cortejo de estos animales. En nuestro caso de estudio, color, pluma y ave se complementan para reforzar un único sentido de fertilidad. También las plumas al surgir desde adentro de las aves, se asocian a la fecundidad (Martínez 1989); en síntesis son muchas las capacidades de estos animales que se derivan de su especie y particularidades que pueden orientar las interpretaciones respecto a la elección de la materia prima de los penachos.

Volviendo a las relaciones espaciales, las figurillas presentan una posición particular y reservada únicamente a ellas, como si se tratara de tres doncellas más al interior de la tumba. Su ubicación al lado izquierdo tampoco pasa desapercibido, en los pueblos andinos dicha orientación se vincula al mundo de los muertos, a la perdida de la energía o fuerza vital, así como a la acción de protección y rechazo de peligros que opera desde no humanos (por ejemplo hilados de torsión zurda) a humanos a partir de la relación de los primeros con las deidades y el lugar de los difuntos (Gisbert et al. 1987; Grebe e Hidalgo 1988; Guaman Poma 1993 [1615]; Platt 2002; López Campeny 2006). Asimismo, Lloq'e también se relaciona con lo femenino, la luna y las aperturas (Estermann 2006). Estos aspectos pueden ser complementarios entre sí, y se encuentran en consonancia con los posibles significados esbozados para los adornos cefálicos de las figurillas. Sillar (2009), a la vez, considera a los sacrificios en las altas cumbres como actos de comunicación entre el poder de las montañas y los lugares representados en las ofrendas realizadas, una manera de iniciar un vínculo reciproco donde la montaña como entidad no humana es capaz de responder con su poder de fertilidad. El sacrificio crea un lazo, una obligación e inicia el intercambio de dones y contradones. En esta ocasión, el ritual podría haber tenido una intención propiciatoria de fertilidad, lluvia, luna, sol y nacimientos (aperturas); mediante la comunicación con las deidades tutelares que reciben ofrendas cargadas de sentido, y quizás también de capacidades y agencia para desempeñarse en el ámbito de los apus y achachilas. 
Adorno cefálico portado por La Doncella

Ubicación en el contexto:

El adorno cefálico analizado se encontraba dispuesto sobre la cabeza de La Doncella. En este caso, el tocado ocupa el centro del contexto funerario en una relación de contigüidad física directa con la joven. Por esta razón, podríamos abordar al adorno cefálico como parte de un ajuar funerario, pero también como constituyente de la joven en sí misma, conformando parte de su identidad. Solo se conocen dos adornos cefálicos semejantes en los andes, recuperados uno en el nevado del Ampato (Perú) y el otro en el Cerro Esmeralda (Chile).

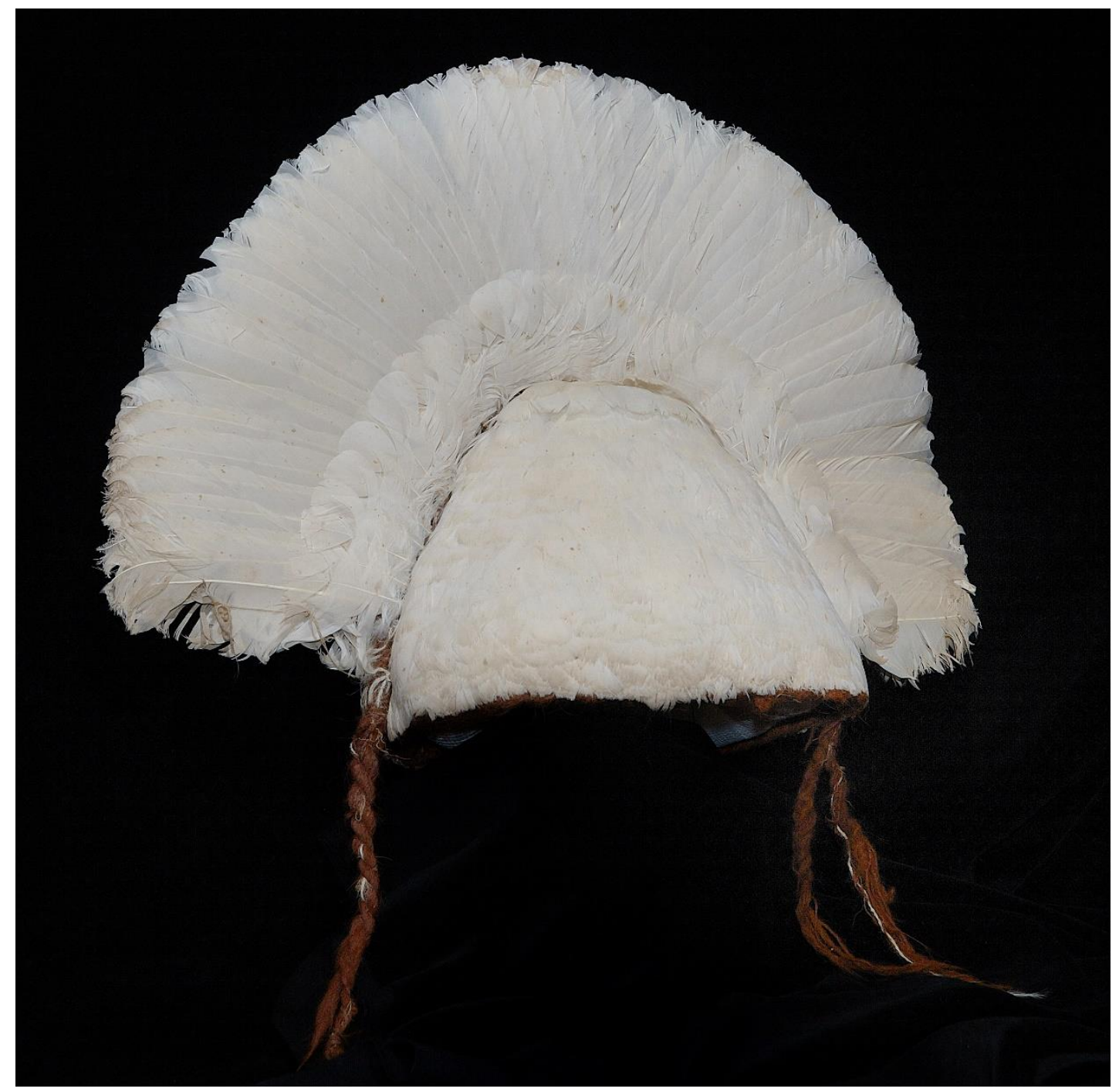

Figura 6: Adorno cefálico portado por La Doncella. Foto: Lisardo Francisco Maggipinto, gentileza MAAM (Museo de Arqueología de Alta Montaña). 
Descripción del adorno cefálico portado por La Doncella:

- Color: Blanco / sin teñir

- Tamaño: El casquete mide $21 \mathrm{~cm}$ de alto, tiene un diámetro de $31 \mathrm{~cm}$ en la base y de $8 \mathrm{~cm}$ en el vértice del cono. El alto total del tocado es de $34 \mathrm{~cm}$ y el ancho máximo de $47 \mathrm{~cm}$ (Ceruti 2003). Presenta un gran tamaño, aunque a diferencia de las figurillas y sus penachos, este no parece más de la mitad de longitud que el cuerpo humano.

- Forma: Semicircular.

- Plumas: Del ala (plumas de vuelo), pertenecientes a parinas o flamencos.

- Manufactura: Las plumas están engarzadas en un gorro confeccionado en algodón, revestido de plumas blancas del cual nacen otras del mismo tipo pero extendidas y desplegadas de forma semicircular (Reinhard 1999). Posee 14 hileras de plumas pequeñas ${ }^{4}(3,5 \mathrm{~cm})$ en el casquete. El penacho está formado por una hilera de plumas medianas $(5,5 \mathrm{~cm})$ sobre una segunda hilera de plumas más grandes de $14 \mathrm{~cm}$ (Ceruti 2003). Cabe destacar que la disposición de las plumas es de tal precisión y similitud a la que podemos encontrar en el pecho del animal, que quizás dicho engarce busque representarlo 5 .

Para el caso del adorno cefálico de La Doncella, los aspectos discutidos respecto a forma, el color y especie a la que pertenecen las plumas son iguales a los descriptos para el tocado de la figurilla de plata, sin embargo su tamaño es más pequeño en relación el cuerpo de la joven y el tipo de plumas empleadas son de vuelo, al parecer provendrían de las alas del ave. Por esta razón el adorno cefálico es además ícono e índice (por semejanza formal, por factorialidad y por contigüidad física) del ala de las aves y del ave en sí misma. En las sociedades aymara, actualmente se realiza una ceremonia llamada pusip' iya para la obtención de buenas cosechas y para lo cual recolectan plumas de parinas (Martinez 1989), algo similar ocurre entre los Chiriwanus de Patacamaya/Umala quienes utilizan una lanza con abundantes plumas de flamenco para invocar las lluvias de noviembre. En estos casos el flamenco aparece, otra vez, como un ave de buen augurio para las cosechas (Sigl y Mendoza Salazar 2012). Las parinas llegan a las zonas altas, luego de haber volado kilómetros de distancia, justo en el momento en que también aparecen las precipitaciones pluviales. En cuanto a la época incaica existe un cuento que vincula a la parina con las lluvias torrenciales (Estrada 1995 citado en Sigl y Mendoza Salazar 2012). Estas aves actúan como signo de la lluvia y la fertilidad, lo que fundamenta la inclusión de sus plumas en las celebraciones rituales, a modo de pedido por años benéficos y prósperos, para lo cual la economía agrícola y pastoril es la base. Quizás el adorno de La Doncella sea la síntesis de distintos elementos presentes en los tocados antes analizados donde se funde el sentido de fecundidad, fertilidad, mediación, vuelo, comunicación entre lo alto y lo bajo, lluvia y nacimiento, todo ello ligado a la representación de la luna. 
Por otro lado, retomando lo mencionado en apartados anteriores, los adornos cefálicos también han marcado límites para cada género y por lo tanto contribuido a la constitución de mujeres y hombres como tales. En tiempos de los incas los hombres solían llevar una honda atada en la cabeza, una faja o en el caso de los cusqueños un llauto, cinta de lana que daba vueltas a la cabeza. Las mujeres usaban bandas cefálicas o vinchas sobre la frente, en tanto las de la nobleza llevaban una prenda textil denominada ñañaqa, textil doblado y acomodado sobre la cabeza (Cobo 1892 [1653]). En el caso de La Doncella, ni ella, ni las miniaturas que la acompañan portan estos tipos de adornos cefálicos. Ceruti (2003) sugiere que quizás "... el tocado de plumas sea un implemento muy importante en la indumentaria ceremonial de las aclllas o mujeres elegidas por el incanato". A través de los dibujos que Guaman Poma nos dejó podemos observar que los adornos cefálicos plumarios, principalmente forman parte de la indumentaria masculina, aunque podemos destacar también el empleo de este tipo de adornos, semejantes al portado por La Doncella, durante las celebraciones del día de los difuntos. Al respecto nos dice Guaman Poma (1993 [1615]: 189) "En este mes sacan los difuntos de sus bóvedas que llaman pucullo, y le dan de comer y beber y le visten con sus vestidos ricos y le ponen plumas en la cabeza, y cantan y danzan con ellos...".

Probablemente, los adornos cefálicos similares al de la joven aclla, fueron empleados en celebraciones especiales. En los dibujos de Guaman Poma, los adornos cefálicos con aureolas de plumas se vinculan principalmente a los habitantes de las tierras bajas, aunque también aparecen representados generales y principales del inca con cascos o chuco con aureola de plumas, cuya morfología es la que más se asemeja al tocado de La Doncella. Por otro lado, los uncus ajedrezados han sido asociados a figuras masculinas, siguiendo a Abal de Russo (2003) se trataría de atuendos usados por personajes dedicados al culto, y según Martínez Armijo (2006) se vincularían a guerreros o líderes militares. La Doncella portaba este tipo de uncu, lo cual sumado a lo mencionado para el adorno cefálico nos lleva a pensar en una transposición de lo masculino hacia ella a partir de la vestimenta. De todas maneras, si bien Guaman Poma no dibuja ninguna mujer con adorno plumario semejante, no debemos descartar la posibilidad de que los mismos fueran utilizados en otros contextos ceremoniales asociados a las mujeres.

Farrington (1998 citado en Ceruti 2003) propone una transformación de la víctima humana en estatuilla, atravesando en su vestimenta el proceso de incaización y estandarización necesario para luego poder ser ofrendada al sol y enterrada del mismo modo que las restantes ofrendas de estilo imperial incaico. Su hipótesis se apoya en la semejanza de la vestimenta de las personas ofrendadas y de las estatuillas, es decir en un principio de iconicidad. En el caso de La Doncella, una de sus estatuillas presenta gran semejanza ya que, como vimos, posee un tocado plumario blanco idéntico al de ella. Independientemente de la hipótesis planteada por el autor, podemos decir que la 
parafernalia que rodea a las miniaturas antropomorfas define a estas como seres particulares, ya sean representantes de personas específicas o deidades (como lo planteado por otros autores Beorchia 1985, Reindhard y Ceruti 2000). De la misma manera la persona ofrendada necesita iguales elementos para convertirse en una más de aquellas estatuillas, cuyos adornos cefálicos se encuentran cargados de sentidos asociados a deidades tutelares como el sol y la luna.

Interpretaciones para nuestro caso de estudio

La detallada confección de la vestimenta de la niña viene a conformar un todo cuidadosamente incluido, que redefinirá a la misma en su nueva identidad social. Es decir, todo aquello que la joven viste y lleva consigo fue incluido para convertirla en una nueva persona o ser, ya que mediante la ceremonia de sacrificio permanecerá junto a los apus, ella misma podría convertirse en parte de estos seres por su unión con ellos. Por lo tanto cada elemento incluido tiene el propósito de redefinir la identidad de esta joven; la vestimenta y ornamentos no solo buscan ser adecuados para integrarse a sus apus, sino también hacer de ella un nuevo ser. Entre esos elementos se encuentra el adorno cefálico como un agente importante en la reconstitución de su persona, fue confeccionado especialmente para ella y en su diseño incorpora restricciones de uso (no cualquiera podrá vestirlo, es de la talla de la joven). De igual manera, el adorno cefálico está en relación de dependencia respecto a la joven, requiere de ella para permanecer suspendido en el aire y dotarse de movimientos; esto permitirá que pueda ser apreciado en todo su esplendor.

El hecho de estar ligado a la cabeza de alguien permite su reconocimiento como parte de esa persona, a la vez que ese individuo también es reconocido como tal por portar un penacho como el analizado. Es decir, tanto adorno cefálico como persona se definen y redefinen de acuerdo a sus relaciones. Por ejemplo, en el caso de La Doncella el adorno queda definido por la sobreimposición de una dimensión identitaria sagrada, ya que la joven es una aclla (virgen del Sol) que por su pureza morara junto a los apus, de esta manera los sentidos asociados a la elegida van a empezar a asociarse también al penacho que porta. Cuando la joven incluya en su persona el uso de este adorno adoptara también una nueva identidad que incorpora los sentidos a los que se asocia el penacho: la luna, la lluvia la fertilidad, lo asociado a las divinidades.

También sabemos que no cualquier persona podía hacer uso de las plumas de aves en el incario, a la vez que, llevar puesto un adorno cefálico con arte plumario era signo de un elevado estatus social, en tanto se requería de la habilidad de especialistas en el tema y de una capacidad adquisitiva determinada (Betancourt 2015). Lo cierto es que este tipo de adorno cefálico lo vemos en las estatuillas y en la joven doncella, por lo que podemos pensar 
que ambas comparten cierta cualidad que las hace merecedoras de un tocado plumario. ¿Cuál es esa cualidad? A nuestro parecer, la respuesta se encuentra asociada a su vínculo con aquellas entidades (deidades) que permiten el buen desarrollo de la vida para una sociedad como la incaica.

Una Deidad puede ser definida como la manifestación de la divinidad. El vínculo entre Divinidad y Deidad puede implicar el empleo de los procedimientos lógicos esbozados por Peirce: analogía, contigüidad, causalidad, factorialidad o consenso. Por ejemplo, el inca por contigüidad (lazos parentales) con Inti (fundamentado en el mito de origen) es expresión de este último, y se convierte en una deidad solar. Una vez visto los elementos vinculables a la luna integrados en la misma doncella y su ajuar, pensamos en una reconfiguración de su persona. Creemos que ella pudo convertirse en una Deidad entendiéndose ello como signo de divinidad, es decir, la joven se transformó en un ser que por alguna razón legitimada podría encontrarse directamente vinculada con la divinidad o la deidad lunar. En ese caso, La Doncella adquirirá el derecho de estima equivalente a los altos dirigentes del imperio y de las deidades andinas. Por lo tanto portar este adorno cefálico imbuía a la niña con su grandeza, fundiéndose simultáneamente con su rostro y sacralidad.

\section{Conclusiones}

Gracias a la evaluación de los adornos cefálicos mediante la clasificación peirciana del signo pudimos determinar que la elección de los mismos como parte del ritual, de la vestimenta de la joven y de las estatuillas tiene poco de arbitrario. También hemos notado y queremos resaltar que los adornos cefálicos, en su diseño y componentes, guardan relación de semejanza y de contigüidad con las aves, seres que muchas veces pasan desapercibidos en las investigaciones arqueológicas. El valor de las plumas, como vimos, puede estar asociado tanto a su relación con animales específicos (probablemente reconocidos por sus capacidades, hábitat y por lo tanto por sus relaciones con el mundo que rodea a los incas y que constituye su cosmología) como a su color. Sin embargo para poder acercarnos más al motivo de inclusión de estas plumas, debemos ahondar en la identificación taxonómica de las especies utilizadas y en los significados otorgados a estas aves por parte de la sociedad incaica, quizás atendiendo a otros contextos donde las mismas se incluyeron.

A lo largo del trabajo, abordamos algunos de los posibles significados para los adornos cefálicos incaicos. A la vez, estos sentidos se refuerzan cuando prestamos atención a los personajes que los acompañan. En el caso de las estatuillas parece ser dominante la idea de fertilidad, ya que se trata de figuras femeninas, incluyendo una confeccionada en mullu reforzando el sentido reproductivo. Cabe agregar, para las figurillas femeninas de oro y 
plata, su carácter opuesto y complementario entre sí. Ambas están abarcando la dualidad noche-día/ luna-sol, ampliamente expresada en numerosos ámbitos de la vida de la sociedad andina para el momento incaico (Cox 2002). En tanto la figura de mullu cumple un papel diferente de las estatuillas arriba mencionadas, las confecciones en conchas de Spondylus son frecuentes en los santuarios de altura, lo que estaría reafirmando la conexión simbólica de las montañas y la Mamacocha, "madres de todas las aguas" (Quevedo y Duran 1992). La estatuilla mencionada, carece de adorno cefálico, pero su materia prima (mullu) fortalece su vínculo con el mar y realza la dimensión dual y de complementariedad entre las zonas bajas (costa) y altas (montaña) donde fue depositada definitivamente. Las estatuillas, además pueden comprenderse como elementos otorgados por los propios dioses (montañas en el caso de la plata y el oro, océano para el caso del mullu) al igual que las illas y que, por lo tanto, vienen a facilitar la comunicación con los mismos. Todo esto está en consonancia con los sentidos expresados por los adornos cefálicos, los cuales incluyen características vinculables a las deidades lunar y solar, como la forma y el color; pero también expresan contenidos específicos (no solo asociados a las capacidades y características de estas deidades, sino también a las de aquellas aves que aportaron las plumas): la lluvia, la fecundidad, lo alto y lo bajo, la comunicación entre ambos. De todos ellos, el más recurrente es la fecundidad y fertilidad, lo cual podemos proponer como el motivo de la ceremonia. Pero en ese caso, ¿Qué clase de fecundidad se está buscando? como dijimos, podría ser agrícola y/o también social, sin embargo aproximarnos a ello requeriría profundizar los análisis e incluir al resto de objetos presentes en la tumba. Sumar nuevos contextos correspondientes a la ceremonia de Capacocha en las altas cumbres permitirá realizar un estudio comparativo que nos aproxime a las cuestiones que quedaron por resolver, como por ejemplo el uso diferencial de plumas para la elaboración de los tocados de las estatuillas. Esto nos llevará a identificar patrones de selección de cierto tipo de plumas o especies de aves para objetos específicos, lo cual podría estar asociado a su significado. Esta cuestión fue planteada por nosotros para el tocado de la figurilla masculina en relación a las femeninas pero, al no constituir parte de nuestro objetivo, no fue puesta en contraste con otros casos. Frente a ello la semiótica se ofrece como un camino fértil para desentrañar sentidos perdidos y difusos en los contextos arqueológicos.

El análisis semiótico nos permite hacer explícitos y visibles los razonamientos que dan sentido a las cosas, que las mantienen vinculadas y que permiten sostener nuestras interpretaciones. En este artículo observamos que la indexicalidad y la iconicidad son elementos importantes en el pensamiento andino, y son empleadas para significar las cosas con mayor recurrencia que el consenso o la arbitrariedad. El análisis semiótico nos permite reconstruir vínculos perdidos o no claramente percibidos. Adentrarnos en los razonamientos que tejen el entramado que da sentido a su mundo, podemos acercarnos 
poco a poco a la cosmología de estos pueblos. Este trabajo es apenas un esbozo de ello, pero también un ejemplo de los caminos posibles a tomar.

Agradecimientos: a Álvaro Martel y Silvia Giraudo por guiarme en este trabajo y darme las herramientas teóricas necesarias. A Pablo Flores por su incondicional apoyo y cariño. A Soledad Martínez por su consejo y aliento. Quiero agradecer también al Museo de Arqueología de Alta Montaña y, especialmente, a Lisardo Maggipinto por poner a mi disposición las fotos requeridas para este trabajo.

\section{Notas}

1- El signo según Peirce se define como "Una cosa que está en lugar de otra a los ojos de alguien, bajo ciertos aspectos o capacidades" (Preucel 2006: 54). Debemos aclarar que Charles Peirce no publicó ninguno de sus trabajos y solo se conoce su obra a partir de lo que sus alumnos han dado a conocer sobre ella.

2- Si bien el reducido número de hallazgos de este tipo puede deberse a motivos de conservación, el arte rupestre es una evidencia que atestigua su uso diferencial, apoyando esta hipótesis.

3- Hasta el momento otros investigadores llevaron a cabo una identificación expeditiva sobre algunos adornos cefálicos pero sin constatación científica (Christian Vitry com. pers. 2015). Aún no se han realizado estudios detallados que impliquen el uso de colecciones de referencia o análisis microscópicos para la determinación taxonómica de las plumas que conforman los objetos.

4- Estas podrían corresponder a plumas del cuerpo o cobertoras alares (semiplumas), sin embargo no podemos estar seguros debido a que no tuvimos acceso a las piezas originales, razón por la cual la identificación se llevó a cabo a partir de fotografías, a partir de los criterios planteados en Velardez Fresia et al. (2018).

5- Pareciera ser la misma piel de la parina adherida sobre la base del casquete, sin embargo no podemos estar seguros si el tipo de pluma corresponde a las del cuerpo del ave debido a que no tuvimos acceso a la pieza para analizarla con mayor detalle.

\section{Bibliografía citada}

Abal de Russo, C.

2003 Tílla, collcapata o unku ajedrezado: vestimenta de algunas estatuillas exvoto procedentes de waka incaicas de altura. En Tejiendo Sueños en el Cono Sur. Textiles Andinos: Pasado, Presente y Futuro. Actas del Simposio ARQ-21, 51 Congreso Internacional de Americanistas, pp. 223-235. Santiago de Chile. 
Agüero, C.

1994 Clasificación de turbantes del Periodo Formativo Temprano en el Norte de Chile. Boletín del Comité Nacional de Conservación Textil 2: 61-70.

1995 Indicadores textiles de grupos formativos proposición de una tipología de turbantes. En Hombre y Desierto. Una perspectiva cultural. Actas del XIII Congreso Nacional de Arqueología Chilena, tomo II, pp. 97-114. Antofagasta.

Beorchia, A.

1985 El Enigma de los Santuarios Indígenas de Alta Montaña. Centro de Investigaciones Arqueológicas de Alta Montaña, San Juan.

Berenguer, J.

1993 Gorros, identidad e interacción en el desierto chileno antes y después del colapso Tiwanaku. En Identidad y Prestigio en los Andes. Gorros, Turbantes y Diademas, pp. 41-64. Museo Chileno de Arte Precolombino, Santiago de Chile.

2006. Señales en la cabeza. Los tocados de Wirakocha en el norte de Chile. En Catálogo de la Exposición Gorros del Desierto. Museo Chileno de Arte Precolombino, Santiago de Chile.

Betancourt, C.

2015 El Poder de las Plumas. Colección de Arte Plumario del Museo Nacional de Etnografía y Folklore, según la Cadena de Producción. Musef, La Paz.

Cereceda, V.

1990 A partir de los colores de un pájaro. Boletín del Museo Chileno de Arte Precolombino 4: 57104.

2010 Semiología de los textiles andinos: las talegas de Isluga. Chungara 42(1): 181-198.

Ceruti, C.

2003 Llullaillaco. Sacrificio y Ofrendas en un Santuario Inca de Alta Montaña. Publicación del Instituto de Investigaciones de Alta Montaña, Universidad Católica, Salta.

Cobo, B.

1892 [1653] Historia del Nuevo Mundo, Tomo II. Imprenta de E. Rasco, Sevilla.

Cox, V.

2002 Guaman Poma de Ayala: Entre los Conceptos Andino y Europeo de Tiempo. Centro de Estudios Regionales Andinos Bartolomé de Las Casas, Cuzco.

D’Altroy, T.

2003 Los Incas. Editorial Ariel, Madrid. 
Descola, P.

2012 Más Allá de Naturaleza y Cultura. Amorrortu Editores, Buenos Aires.

Estermann, J.

2006 Filosofía Andina: Sabiduría Indígena para un Mundo Nuevo. ISEAT, La Paz.

Frazer, J.

1915 The Golden Bough: a Study in Magic and Religion. MacMillan, London.

Gallardo, F.

1993 La sustancia privilegiada: turbantes, poder y simbolismo en el Formativo del norte de Chile. En Identidad y Prestigio en los Andes. Gorros, Turbantes y Diademas, pp. 11-25. Museo Chileno de Arte Precolombino, Santiago de Chile.

Gisbert T.; Arce, S. y M. Cajías

1987 Arte Textil y Mundo Andino. Gisbert y Cía, La Paz.

Grebe, M. y B. Hidalgo

1988 Simbolismo atacameño: un aporte etnológico a la comprensión de significados culturales. Revista Chilena de Antropología 7: 75-97.

Guaman Poma de Ayala, F.

1993 [1615] Nueva Crónica y Buen Gobierno I. Fondo de Cultura Económica, México.

Gutiérrez Usillos, A.

2002 Dioses, Símbolos y Alimentación en los Andes, Interrelación Hombre-Fauna en el Ecuador Prehispánico. Ediciones Abya-Yala, Quito.

Hermosilla, N y M. Barrera

2010. Calama, antiguos habitantes del oasis. En Actas del XVII Congreso Nacional de Arqueología Chilena, pp. 107-117. Valdivia.

Horta Tricallotis, H.

2000 Diademas de plumas en entierros de la costa del norte de Chile: ¿evidencias de la vestimenta de una posible parcialidad pescadora? Chungara 32(2): 235-243.

Knappett, C.

2011 Thinking through Material Culture: An Interdisciplinary Perspective. University of Pennsylvania, Philadelphia. 
Latour, B.

2005. Ressembling the Social. An Introduction to Actor Network Theory. Oxford University. Oxford, Reino Unido.

Law, J. y A. Mol

2008 The actor-enacted: cumbrian sheep in 2001. En Material Agency: Towards a Nonanthropocentric Approach, C. Knappett y L. Malafouris (eds.), pp. 57-78. Springer Science \& Business Media, New York.

Levi Strauss, C.

1971. De la Miel a las Cenizas. Fondo de Cultura Económica, México.

Lewis, R.

2016 Panorama Etnográfico de los Tres Grupos Étnicos del Trópico de Cochabamba (YuracarésTrinitaios-Yuquis) con relación a las Aves. UMSS, Producciones CIMA Editores, La Paz.

\section{López Campeny, S.}

2006 El poder de torcer, anudar y trenzar a través de los siglos: textiles y ritual funerario en la puna meridional Argentina. Cuadernos del Instituto Nacional de Antropología y Pensamiento Latinoamericano 21: 143-155.

Magariños de Morentin J.

2003 Hacia una Semiótica Indicial: Acerca de la Interpretación de los Objetos y los Comportamientos. Ediciós do Castro, España.

Marafioti, R.

2005 Charles Peirce: El Éxtasis de los Signos. Biblos, Buenos Aires.

Martinez, J.

1989 Plumas de los dioses. En Catálogo de la Exposición Plumas de los Dioses. Museo Chileno de Arte Precolombino, Santiago de Chile.

Martínez Armijo, I.

2006 Vestimenta de las estatuillas antropomorfas incas en el contexto de la capacocha: un estudio preliminar. En Libro de Resúmenes del XXVIII Congreso Internacional de Americanística, pp. 231-237. Mérida.

Mignone, $\mathrm{P}$.

2009 Miniaturas zoomorfas del volcán Llullaillaco y contraste entre régimen estatal y vida comunitaria en la Capacocha. Boletín del Museo Chileno de Arte Precolombino 14(1): 55-68. 
Museo Nacional de Etnografía y Folklore (Musef)

2014 Vistiendo la Cabeza: Gorros, Tiempo e Identidades. Musef Editores, La Paz.

Nielsen, A.

2007 Bajo el hechizo de los emblemas: políticas corporativas y trafico interregional en los Andes circumpuneños. Producción y Circulación Prehispánicas de Bienes en el Sur Andino, A. Nielsen, M. Rivolta, V. Seldes, M. Vázquez y P. Mercolli (eds.), pp. 393-411. Editorial Brujas, Córdoba.

Platt, T.

2001 El feto agresivo. Parto, formación de la persona y mito-historia en los Andes. Anuario de Estudios Americanos 58(2): 633-678.

Preucel, R.

2006 Archaeological Semiotics. Blackwell Publishing, Malden.

Quevedo, S. y E. Durán

1992 Ofrendas a los dioses en las montañas: santuarios de altura en la cultura inka. Boletín del Museo Historia Natural de Chile 43: 193-206.

Reinhard, J.

1999 A 6700 metros niños incas sacrificados quedaron congelados en el tiempo. National Geographic 5(5): 36-55.

Reinhard, J. y M. Ceruti

2000 Investigaciones Arqueológicas en el Volcán Llullaillaco. Complejo Ceremonial Incaico de Alta Montaña. Editorial de la Universidad Católica, Salta.

Reynaga Berumen, P. y C. Vidales Gonzáles

2013 Una mirada semiótica y comunicativa a la cultura: del cuerpo y el adorno a la construcción social de sentido. Estudios sobre las Culturas Contemporáneas XIX(37): 67-98.

Sanfuentes Echeverría, O.

2011 En torno a la fabricación de una figura simbólica: la cabeza del inca en las representaciones coloniales. Diálogo Andino 37: 21-34.

Schobinger, J.

1999 Los santuarios de altura incaicos y el Aconcagua: aspectos generales e interpretativos. Relaciones de la Sociedad Argentina de Antropología XXIV: 7-27. 
Sigl, E. y D. Mendoza Salazar

2012 No se Baila así no Más...Danzas de Bolivia. Tomo II. Disponible en:

https://www.academia.edu/11318809/No_se_baila_as\%C3\%AD_no_m\%C3\%A1s_Danzas_de_Bolivia

Sillar, B.

2009 The social agency of things? Animism and materiality in the Andes. Cambridge Archaeological Journal 19(3): 369-379.

Siracusano, G.

2005 Colores en los Andes. Hacer, saber y poder. Catálogo de Exposición Museo de Arte Hispanoamericano Isaac Fernández Blanco. Nuevo Mundo Mundos Nuevos. Disponible en http:/ / nuevomundo.revues.org/optika/6/present.html. Consulta: Noviembre 20 de 2016.

Velardez Fresia, M.; Flores, P. y D. Ortiz

2018 Hacia una metodología para el análisis macro y microscópico de plumas y su aplicación en arqueología. En Libro de Resúmenes Extendidos del VII Congreso Nacional de Arqueometría, pp. 69-73. Tucumán.

Vitry, C.

2007 Caminos rituales y montañas sagradas. Estudio de la vialidad inka en el Nevado de Chañi, Argentina. Boletín del Museo Chileno de Arte Precolombino 12(2): 69-84. 
